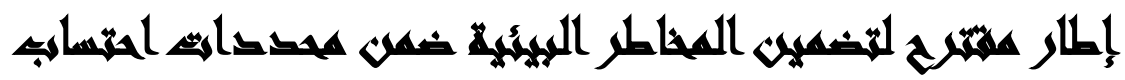

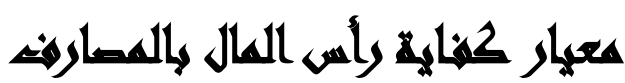

$[1 \wedge]$

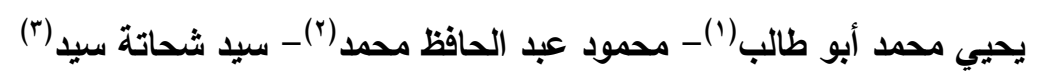

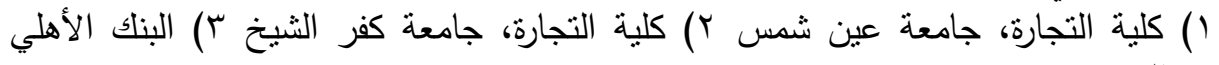
المصري

\section{المستخلس}

وجهت اتفاقية بازل III المصارف إلي ضرورة قبامها بإدارة المخاطر الهامة المرنبطة

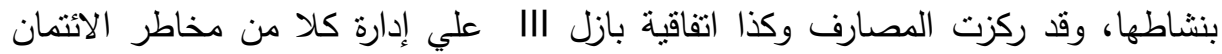

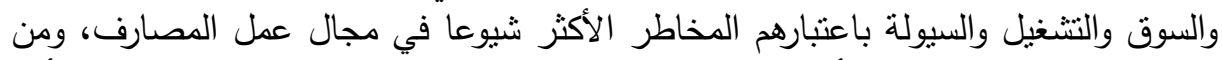

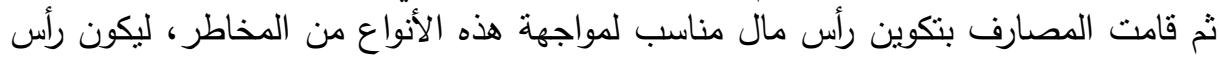

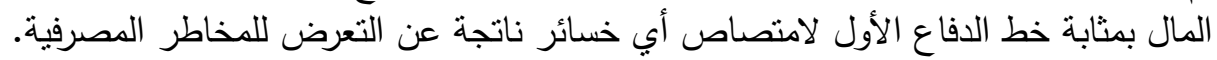

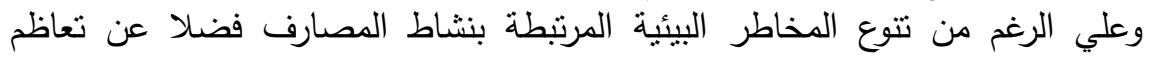

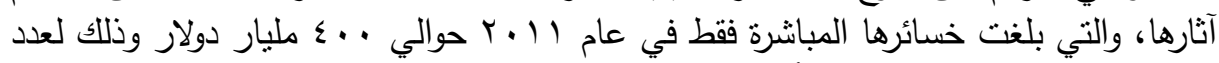

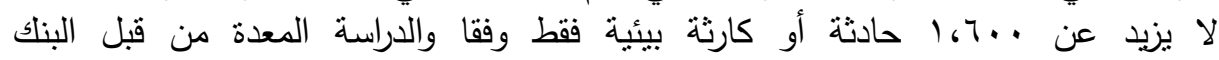

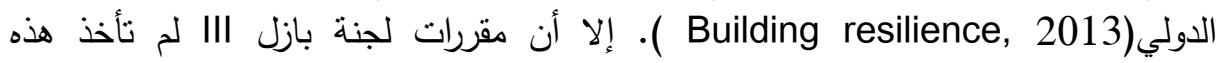

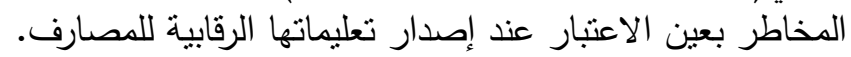

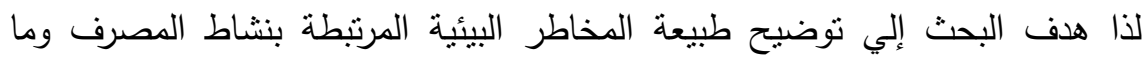

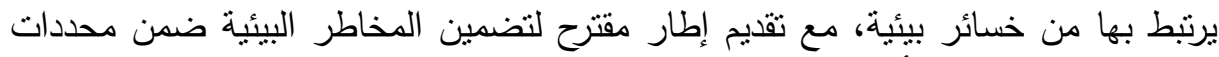

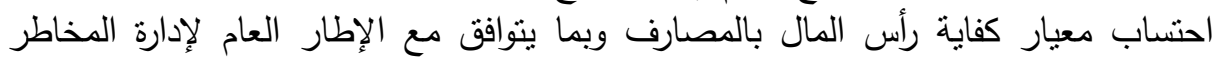

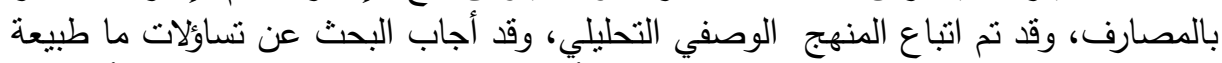

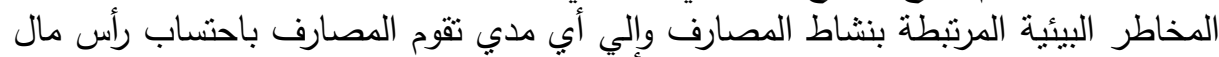

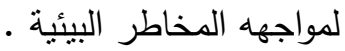

وتم الاعتماد في جمع البيانات علي استخدام قائمة استبيان تم توجيهـا لمفردات عينة

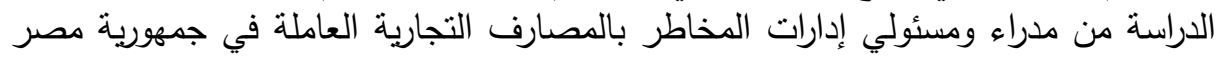

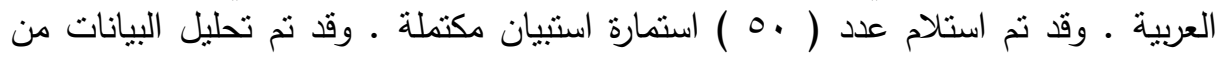

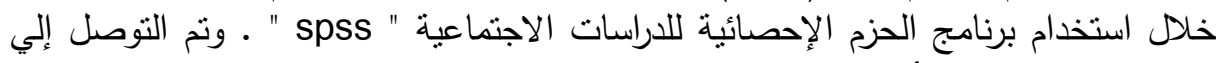

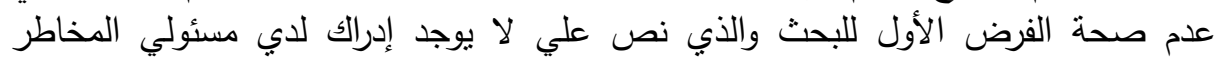

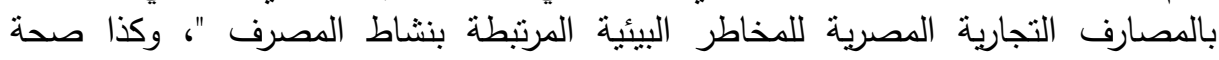

$$
\text { المجلد الأربعون، الجزء الأول، ديسمبر r.lV }
$$


الفرض الثاني والذي نص علي " لا يتم تضمين المخاطر البيئية المرنبطة بنشاط المصرف

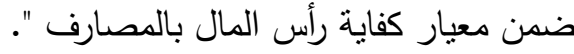

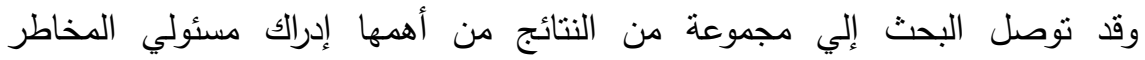

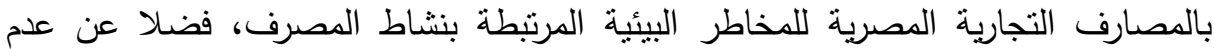

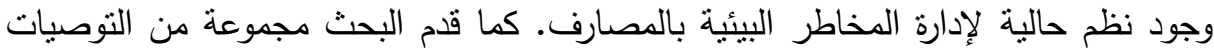

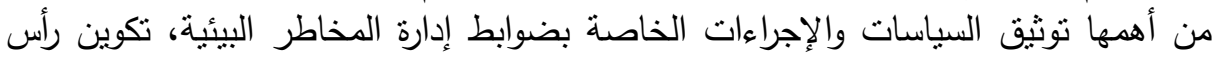

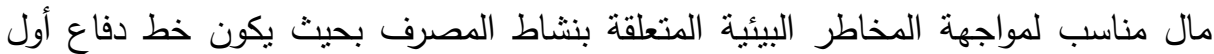

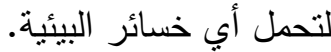

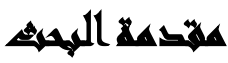

تتعرض الدول للعديد من المخاطر البيئية التي تؤثر سلبا علي اقتصادياتها، وتُحمل هذه

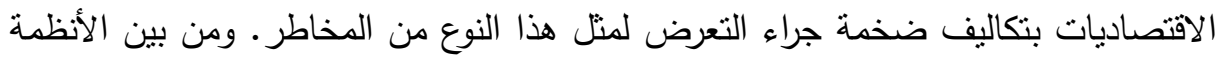

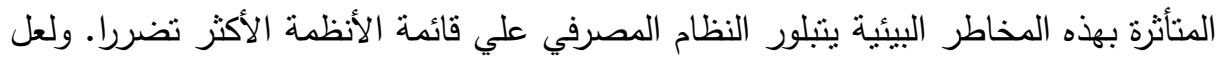

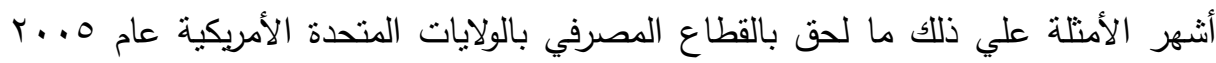
عقب إعصار كاترينا بجنوب ولاية فلوريدا، حيث تسبب الإعصار في تعويضات وخسائر

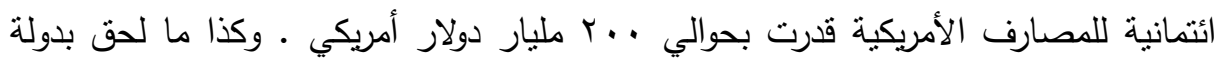
تركيا في عام 1999 من خسائر مالية بسبب سلسلة الزلازل التي خلفت ورائها اقتصاد متداعيا ونظام مالي متهاوي ( Institute For Sustainability Leadership,2014 ). وعلي الرغم من ذلك نجد أن مقررات لجنة بازل III لم تأخذ هذه المخاطر بعين الاعتبار

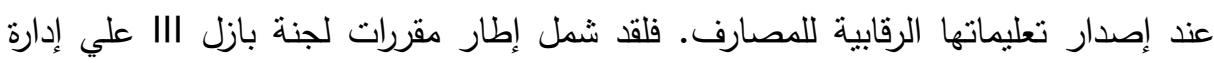

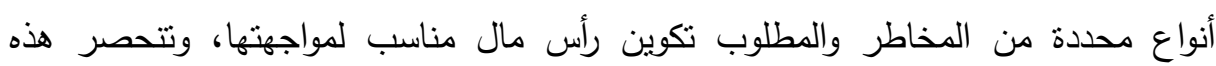

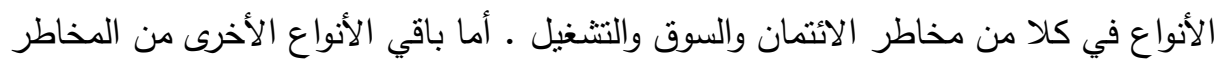

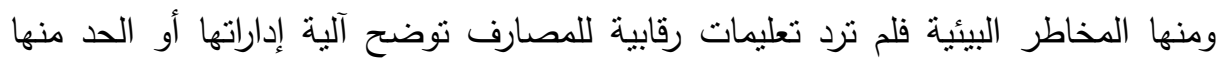
. (Bank of International Settlement,2014) ولذا يقدم البحث إطار مقترح لتضمين المخاطر البيئية ضمن الإطار العام للمخاطر

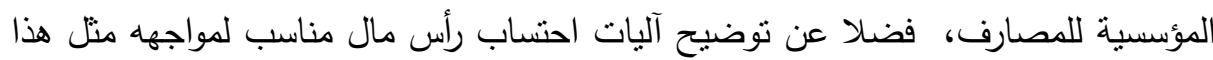


النوع من المخاطر أسوة بما يتم احتسابه من رأس مال لمواجهه المخاطر المالية الأخرى التي

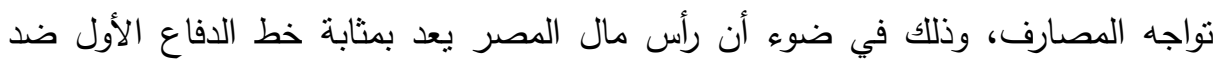
التعرض لأي خسائر قد يواجهها المصرف وأثناء ممارسته لنشاطه.

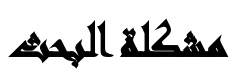

تتمثل مشكلة البحث في عدم تضمين المخاطر البيئية كأحد الأنواع الرئيسية للمخاطر المطلوب إدارتها بالمصارف والمطلوب تكوين رأس مال مناسب لمواجهتها. حيث قامت

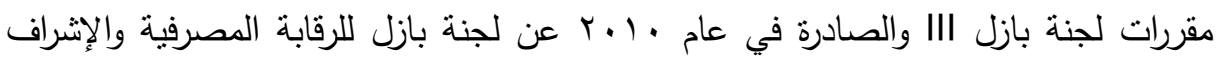

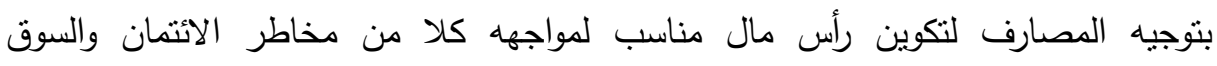

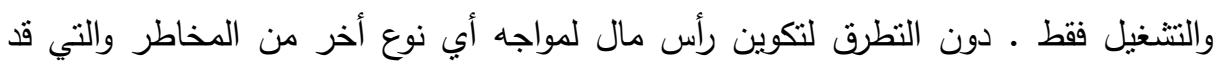
تواجه المصارف ( Bank of International Settlement,2014).

وفي ضوء أن المخاطر البيئية تعتبر من أحد أنواع المخاطر الهامة التي نواجه المصارف في أثناء ممارستها لنشاطها ـ فضلا علي ما أظهرته كلا من دراسة البنك الدولي الني

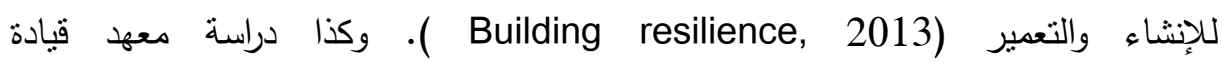

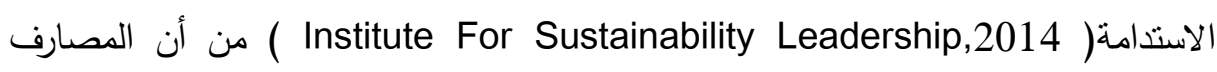
تكبدت خسائر ضخمة نتيجة التعرض لمنل هذا النوع من المخاطر ـ وفي ضوء ذلك تم تقديم

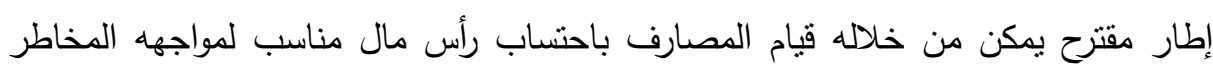
البيئية، أسوة بما يتم احتسابه من رأس مال لمواجهه المخاطر المحددة سلفا من خلال اتفاقية

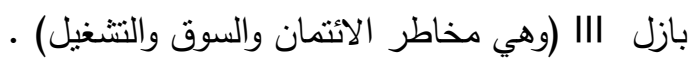

\section{أسهيلال المهمه}

في ضوء مشكلة البحث فإنه يمكن صياغة تساؤلات البحث فيما يلي:

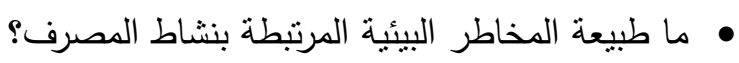

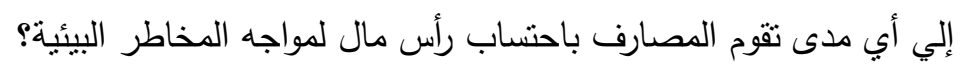

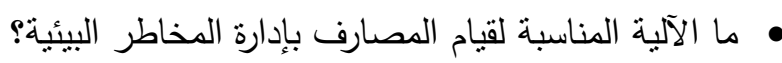

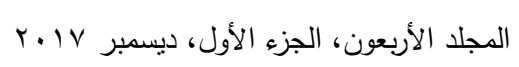




\section{همقهن البهمث}

$$
\text { يتمثل هاف البحث في ما يلي: }
$$

• • توضيح طبيعة المخاطر البيئية المرنبطة بنشاط المصرف.

• تقديم إطار مقترح لتضمين المخاطر البيئية ضمن المخاطر التي يتم احتساب رأس مال

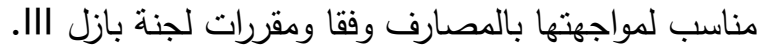
• تقديم آلية لقيام المصارف باحنساب رأس مال مناسب لمواجهه المخاطر البيئية التي تتعرض لها أثناء ممارسه نشاطها.

\section{هغا المهيد}

يمكن صياغة فرضا البحث في الأتي: الفرض الأول: لا يوجد إدراك لاي مسئولي المخاطر بالمصارف التجارية المصرية للمخاطر البيئية المرتبطة بنشاط المصرف. الفرض الثاني: لا يتم تضمين المخاطر البيئية المرنبطة بنشاط المصرف ضمن معيار كفاية

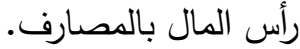

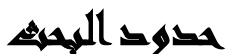

الحدود المكانية: نم إجراء الدراسة الميدانية بالبنك الأهلي المصري وبنك مصر، لذلك يخرج عن نطاق البحث البنوك المتخصصة .

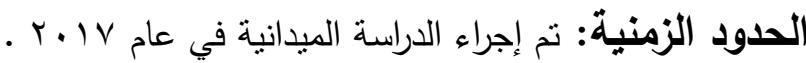

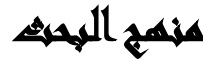

لأغراض تحقيق تساؤلات البحث وأهدافه تم اتباع المنهج الوصفي التحليلي، والذي يعتمد

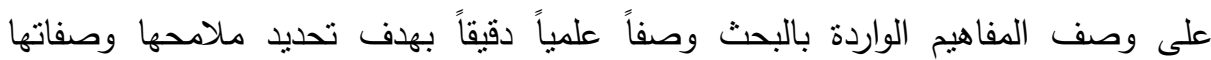


يحيي محمد أبو طالب وآخرون

الخاصة وتمهيداً لتحليلها وبيان النتائج بصورتها الواقعية سواء سلبية أم إيجابية ومن ثم التقييم من أجل الخروج بالتوصيات الملائمة.

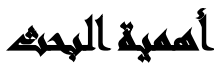

تتمثل أهمية البحث في تقديم إطار مقترح لتضمين المخاطر البيئية ضمن الإطار الحالي

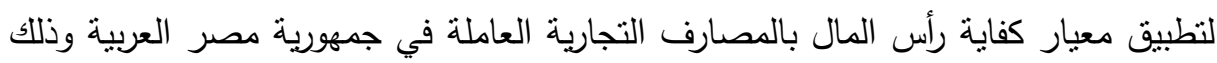

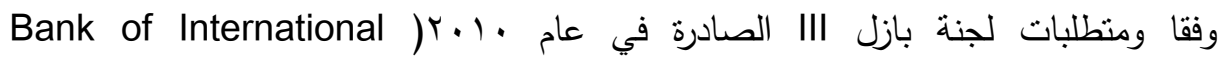

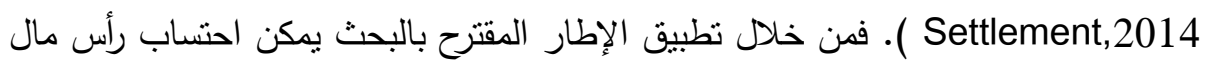

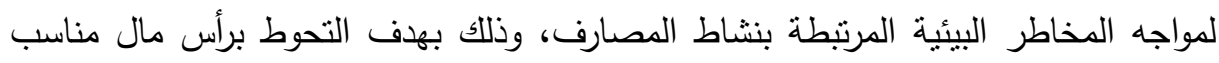
لمواجه المخاطر البيئية أسوة بما يتم احتسابه لمواجهه كلا من مخاطر الائمان والسوق بلهن والتثغيل والسيولة، بما يدعم من الإدارة الفعالة للمخاطر المرتبطة بنشاط المصارف التهابه التجارية العاملة في جمهورية مصر العربية ـ فضلا عن قيام البحث بتقديم مجموعة من التوصيات

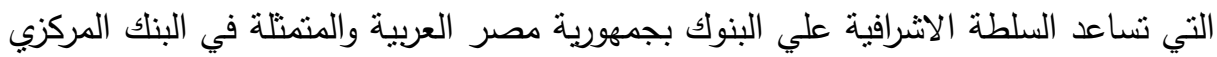

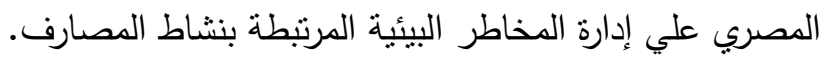

\section{همطلحايت الهحهي}

لجنة بازل: أنشئت هذه اللجنة من خلال بنك التسويات الدولية في عام 19 الم ـ وتكونت لجنة بازل من عضوية rا وكالة للرقابة المصرفية ممثلة في معظم الدول الصناعية، وقد

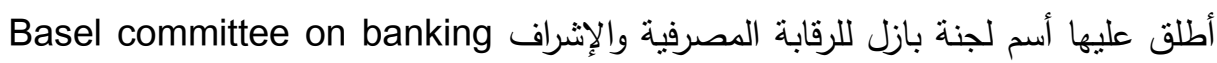
and supervision الإرشادات العامة والضوابط اللازمة المتعلقة بالعمل المصرفي علي مستوي العالم • وفي هذا الصدد فقد أصدرت اللجنة إرشاداتها للمصارف المركزية في صيغة اتفاقيات تم تسميتها

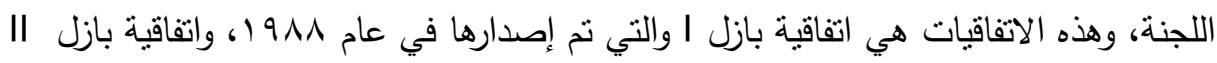

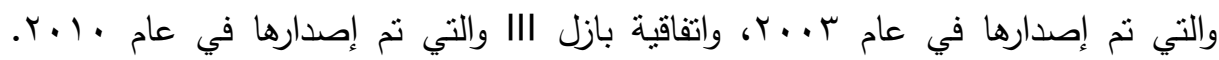
.(Bank of International Settlement,2014)

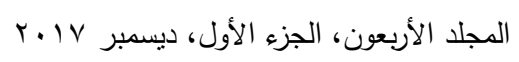


المخاطر البيئية: التهديد المحتمل للمحيط الحيوي جراء ممارسة ألإنسان لأنشطته أو لعوامل طبيعية مما بترتب علية خسائر في الأرواح أو أضرار صحية أخري أو أضرار

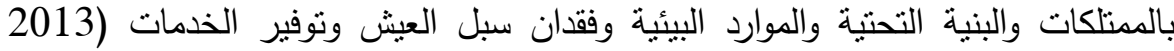

.(Building resilience,

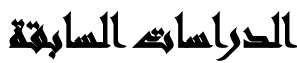

أ- دراسة البنك المركزي المصري(Y Y ب ب): تناولت الدراسة كيفية قيام المصارف

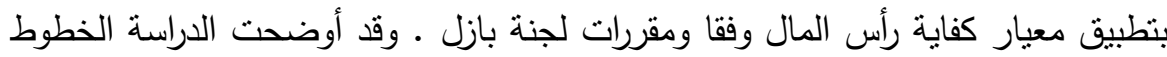

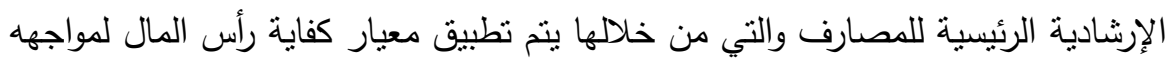

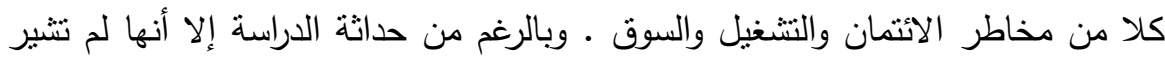

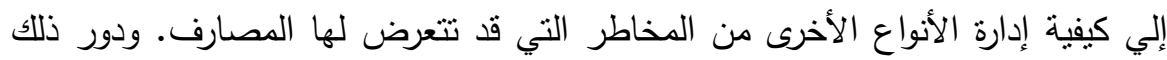

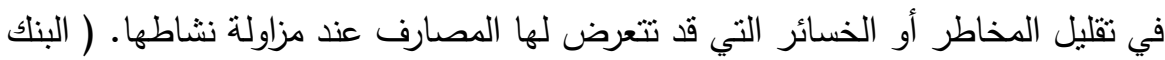

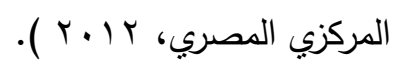
ب- دراسة البنك الدولي للإنثاء والتعمير( ( 1 ـ Y): تعرضت الدراسة لأهم المخاطر

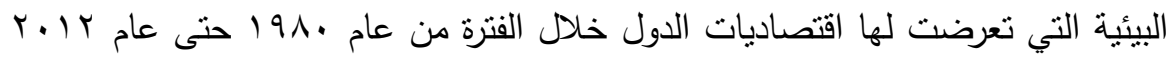

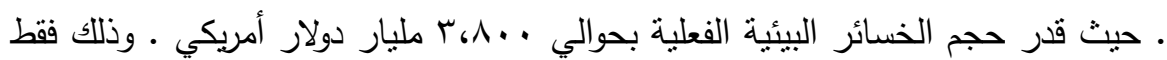

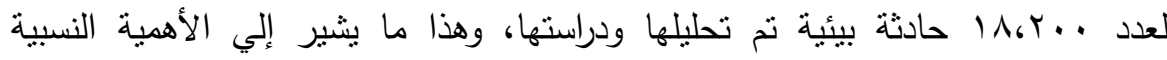
للخسائر البيئة وما يترتب عليها من خسائر (Building resilience, 2013 ).

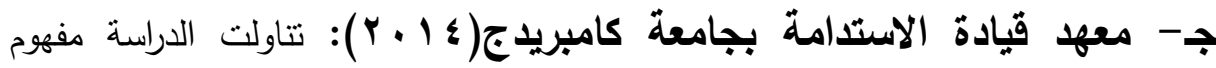
الاستدامة في مجال عمل المصارف مع بحث علاقة المخاطر البيئية بالاستدامة في مجال

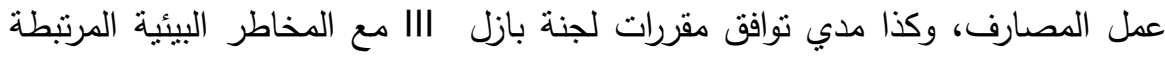

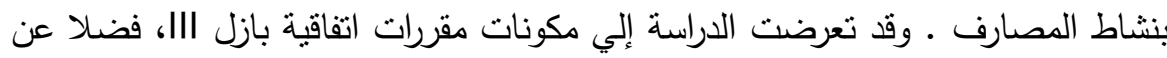
تناول بعض أدوات المصارف المركزية للحد من المخاطر البيئية المرتبطة بنثاط المصارف، منل إصدار سندات التلوث والتي تعتبر بمثابة أداة تقويم للمصارف المرنبة المرنط 
يحيي محمد أبو طالب وآخرون

Institute For Sustainability ) نشاطها بمجموعة من المخاطر البيئية. .( Leadership,2014

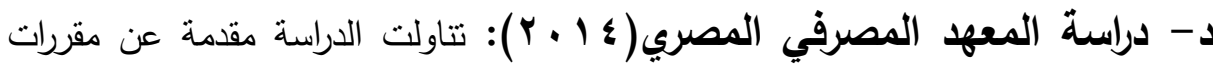
لجنة بازل للرقابة علي المصارف مع تتاول نبذة تاريخية عن بنك التسويات الدولية ومقدمة

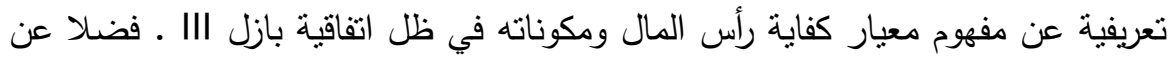

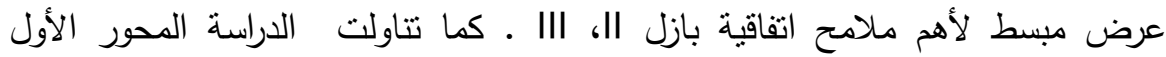

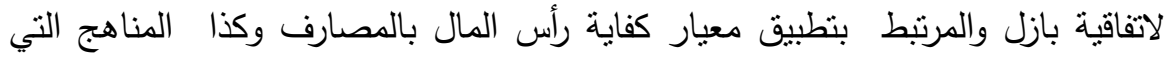
يمكن من خلالها قيام المصارف بتطبيق معيار كفاية رأس المال (المعهد المصرفي

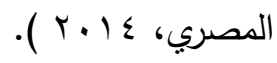

هـ - دراسة إدريس(ع ا • Y): تتاولت الدراسة نوضيح دور المسئولية الاجتماعية

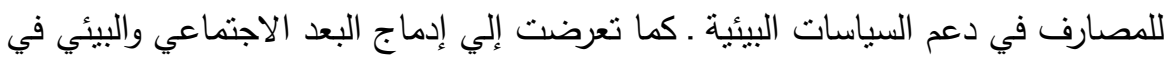
إستراتيجية المصارف بما بضمن مساهنها في دعم السياسات البيئية وتحسين الأداء

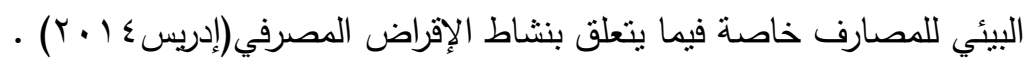

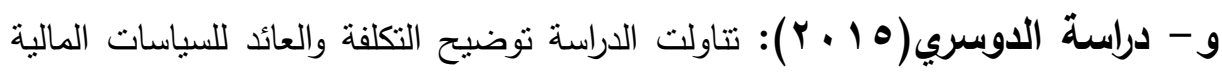

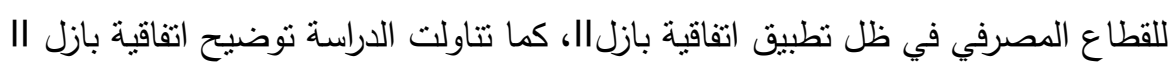

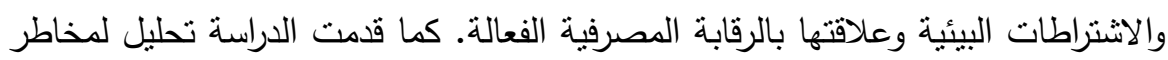
الرقابة المصرفية فضلا عن نتاول الخصائص الجديدة لمقترحات نطبيق معيار كفاية راس

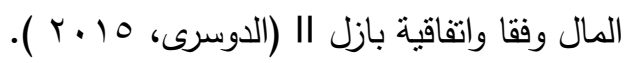

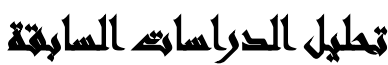

اهتمت الدراسات السابقة بعرض الإطار النظري لتطبيق اتفاقية بازل III للمصارف، مع تحديد المفاهيم المتعلقة بتطبيق معيار كفاية رأس المال وتطبيقه بالمصارف ـ ـ إلا أنها اقتصرت علي توضيح الضوابط والإرشادات العامة دون التطرق إلي النواحي التفصيلية التي لني ينطلبها احتساب رأس المال اللازم لمواجهه كل نوع من أنواع المخاطر المصرفية نطاق تطبيق

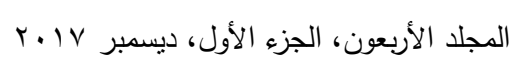


معيار كفاية رأس المال (مخاطر الايتمان والسوق والتتغيل )، كما تطرقت الدراسات إلي

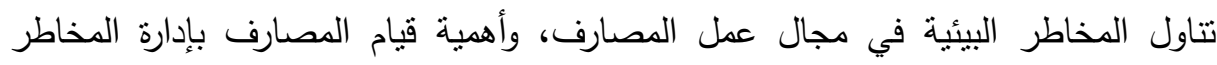

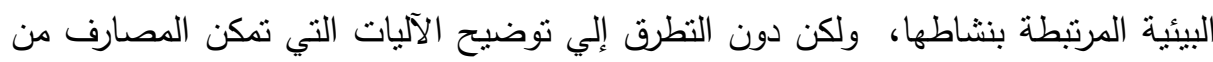

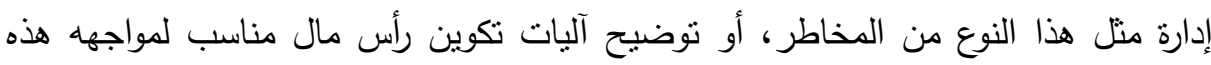

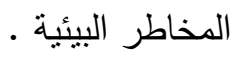

\section{خطلة وإلبراعاهي المهيه}

في ضوء مشكلة البحث التي تم صياغتها فقد تم تفنيا محتويات البحث إلي المباحث

التالية:

$$
\text { المبحث الأول: الإطار النظري للبحث }
$$

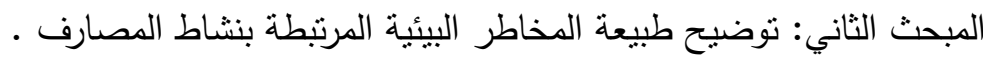

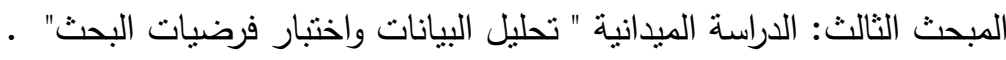

المبحث الرابع: نموذج مقترح لتضمين المخاطر البيئية ضمن محددات احتساب معيار كفاية رأس المال بالمصارف.

\section{المهنه الأول الإسار النظظيى اللهبهي}

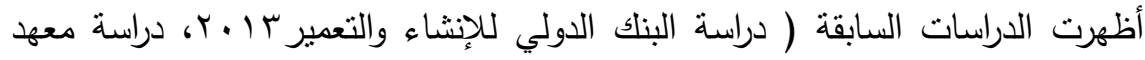

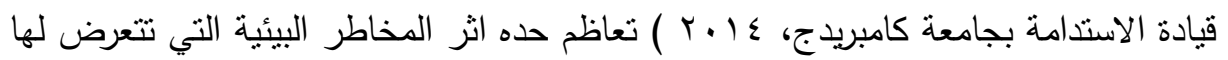
اقتصاديات الدول ووما يرتبط بذلك من خسائر بيئية تلحق بالمصارف والمؤسسات المالية بها

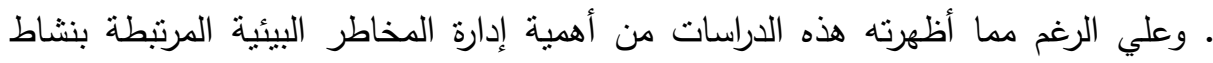

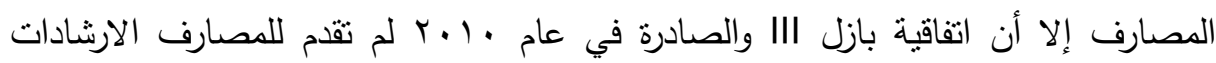

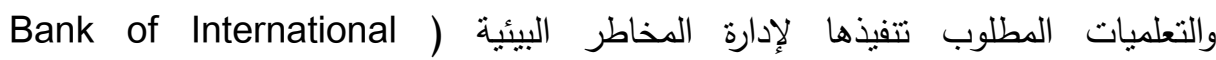


ولذا لا يمكن إغفال الخسائر البيئية المرتبطة بنشاط المصارف والتي قد تُحملها بتكاليف

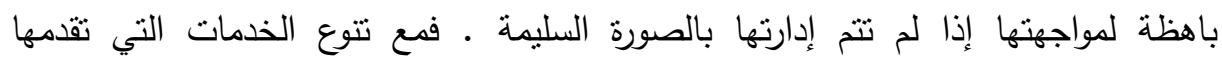
المصارف وما اقترن بذلك من تعقد درجة التكنولوجيا المستخدمة وكذا زيادة درجة التأثير السلبي علي البيئة. فإن ذلك يتطلب قيام المصارف بتضندين إدارة المخاطر البيئية المرتبطة

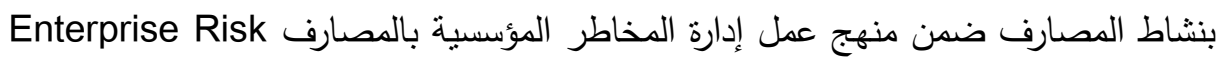
Management مناسب لمواجه المخاطر البيئية المرتبطة بنشاط المصرف. إن اتفاقية بازل III شكلت مجموعة من التدابير الإصلاحية التي هدفت إلي تعزيز

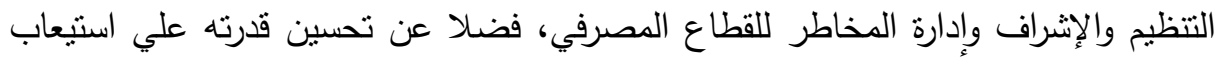
اثر اللازمات المالية، إلا أنها لم تتطرق لقيام المصارف بتكوين رأس مال مناسب لمواجها المخاطر البيئية المرنبطة بنشاط المصارف، لذا يقدم البحث إطار مقترح يوضح كيفية قيام

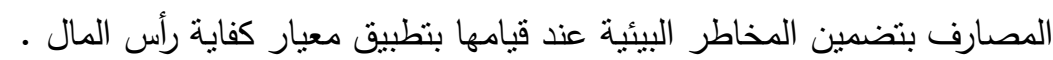

\section{المهبهـ المخانيه}

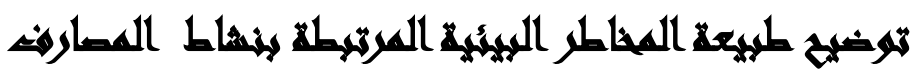

يمكن تعريف المخاطر البيئية علي أنها " التهديد المحتمل للمحيط الحيوي جراء ممارسة

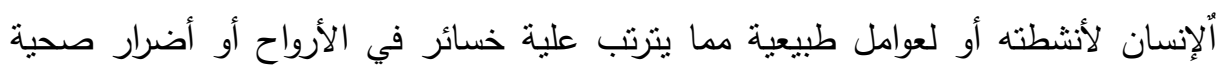

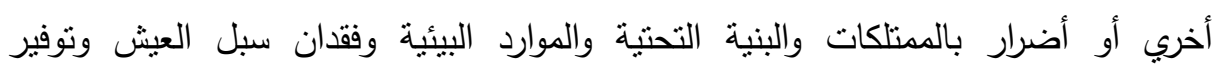
الخدمات. وفي دراسة أعدها البنك الدولي لإنثاء والتعمير لتقدير الخسائر البيئية التي تحملتها

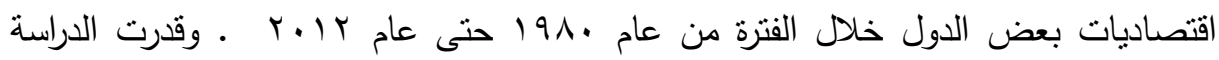

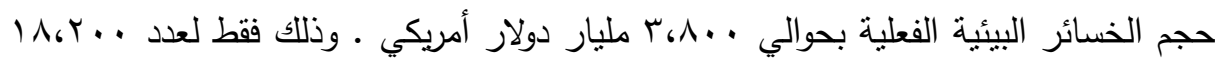

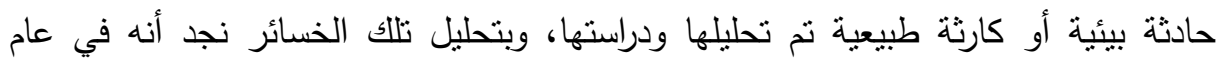

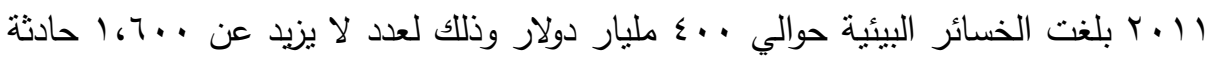

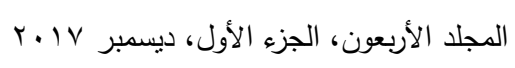




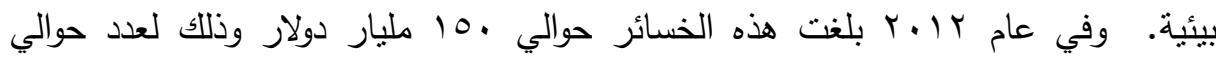
. Building resilience, 2013) .

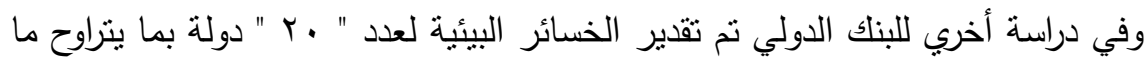

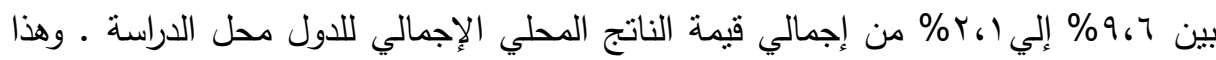

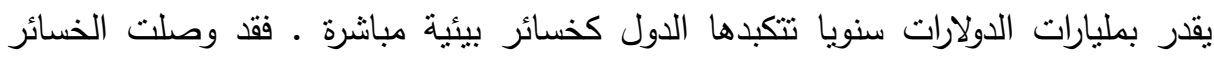
البيئية إلي حوالي 7،9 \% من إجمالي الناتج المحلي لدولة غانا، 9 \% م من إجمالي الناتج

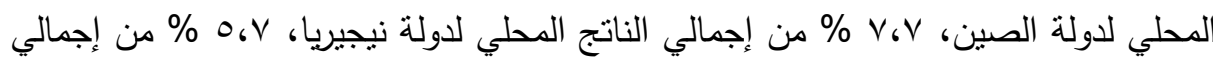
الناتج المحلي لدولة الهند، ^،؛ ؛ م من إجمالي الناتج المحلي لجمهورية مصر العربية .( The world bank, 2013)

ومن كل ما سبق عرضة فإنه يمكن استتباط أن طبيعة الخسائر البيئية تتسم بالضخامة

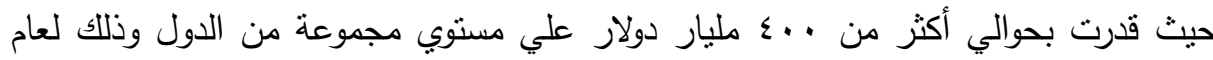

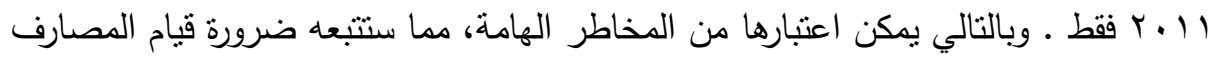
باحتساب رأس مال مناسب لمواجهه تلك النوعية من المخاطر وذلك وفقا وما نصت عند علية اتفاقية بازل III ـ من ضرورة قيام المصارف باحتساب رأس مال مناسب لمواجهه المخاطر الهامة المرتبطة بنشاط المصرف.

\section{المهيش المخالهث}

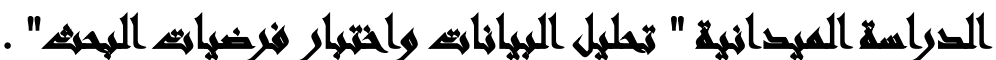

تحليل البيانات: نم الاعتماد في جمع بيانات الدراسة الميدانية علي استخدام قائمة استبيان تم توجيهها لأفراد العينة من مدراء وموظفي المصارف " بواقع عدد ( •0 ) استمارة استبيان"

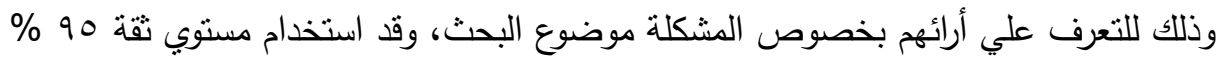
لاختبار صحة الفروض وتعميم النتائج • وقد نم تقسيم استمارة الاستبيان إلي قسمين رئيسيين

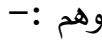
القسم الأول: يمثل الخصائص الثخصية عن الثخص القائم باستيفاء الاستبيان . 
القسم الثاني: يمثل الفقرات التي تم من خلالها تجميع البيانات حول مجالات الدارسة، وتن تقسيمها إلي مجموعتين، المجموعة الأولي تتاولت العبارات من رقم (1) إلي رقم (؟) حول إدراك مدراء المخاطر لإدارة المخاطر البيئية، وتمنلت المجموعة الثانية في العبارات من رقم

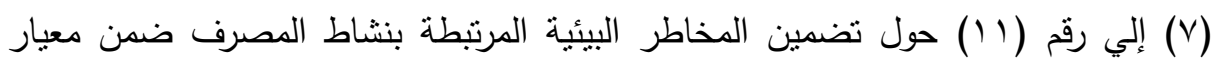
كفاية رأس المال بالمصارف

جدول(1): وقد نم استخدام مقياس ليكرت الخماسي لقياس استجابات إفراد العينة لفقرات

\begin{tabular}{|c|c|c|c|c|c|}
\hline & & & \multicolumn{3}{|c|}{ الاستبيان وفقا وما يلي: } \\
\hline لا آعلم & لا آوافق بشدة & لا أوافت & موافق & موافق بشدة & الاستجابة \\
\hline 1 & $T$ & 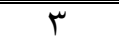 & $\xi$ & 0 & الدرجة \\
\hline
\end{tabular}
الأدوات الإحصائية المستخدمة في البحث تم الاعتماد علي برنامج الحزم الإحصائية للاراسات الاجتماعية spss، وتم إجراء

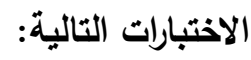

اختبار التوزيع الطبيعي وذلك للتعرف علي ما إذا كانت البيانات تتبع التوزيع الطبيعي من

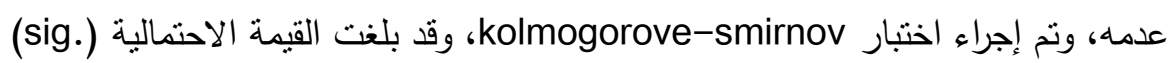

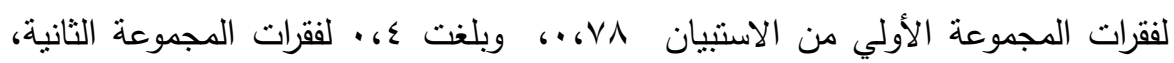

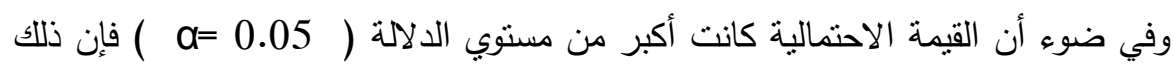
يدل علي أن نوزيع البيانات يتبع التوزيع الطبيعي، وسيتم استخدام الاختبارات المعلمية لاختبار فروض البحث.

تم إجراء اختبار الفا كرونباخ لتحديد مدي ثبات أداة الدراسة الميدانية، وبلغت قيمة معامل الثبات ای \% \%، مما يشير إلي إمكانية الاعتماد علي نتائج الاستبيان.

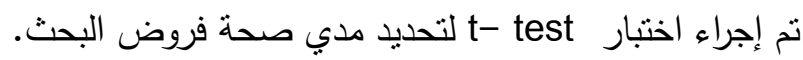

اختبار فروض البحث: نص الفرض الأول للبحث علي أنه " لا يوجد إدراك لدي مسئولي

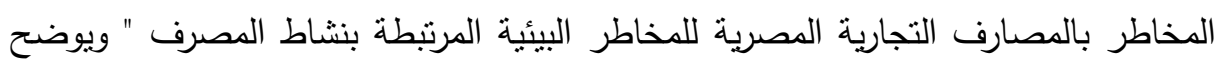

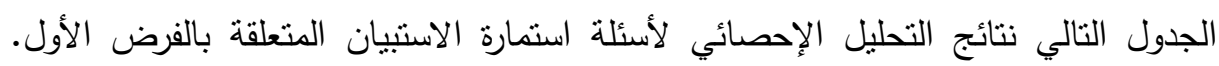

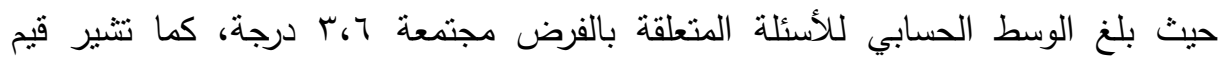

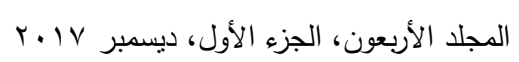


الانحرافات المعيارية للإجابات والتي تراوحت بين (9VA، . - VYVI، · ) إلى الانسجام في آراء

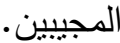

وبهدف التحقق من الدلالة الإحصائية للنتائج السابقة و لاختبار الفرضية الأولى تم

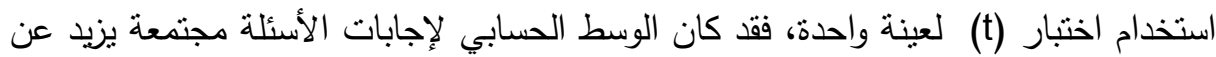

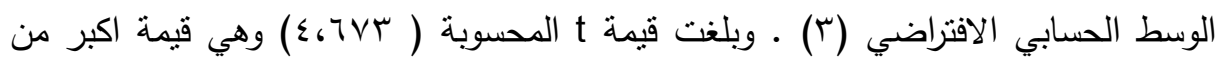

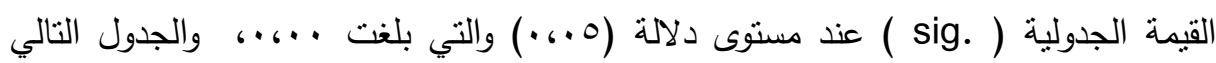
يوضح نتائج آراء أفراد العينة حول الفرض الأله الأول.

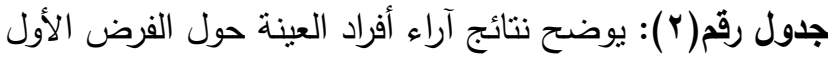

\begin{tabular}{|c|c|c|c|}
\hline المعياري & الوابط & العبارة & العبارة - ماقة \\
\hline$\cdot, \wedge 9 \wedge$ & $r, v$ & 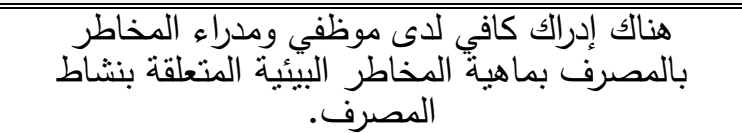 & 1 \\
\hline$\cdot, 9 \vee \wedge$ & $r, \tau$ & 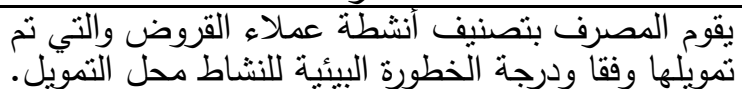 & r \\
\hline$\cdot, \vee \vee \neg \vee$ & $r, q$ & 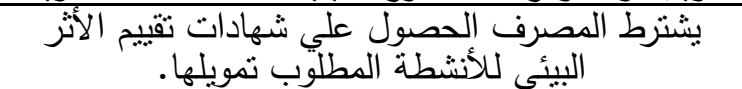 & r \\
\hline$\cdot, \wedge \wedge \vee$ & $r, r$ & 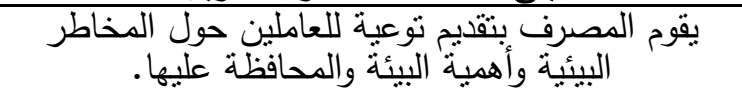 & $\varepsilon$ \\
\hline$\cdot, \wedge \vee 0$ & $r, q$ & 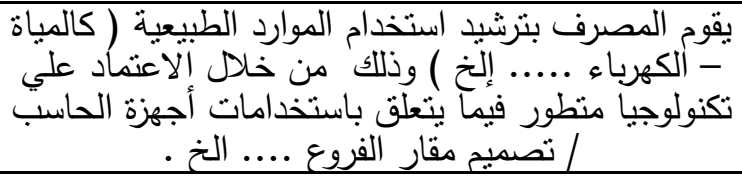 & 0 \\
\hline • • & $r, 0$ & توجد رؤية واضحة لدى إدارة المصرف ل لمفهوم المخاطر & 7 \\
\hline$\cdot, 9 \cdot 7$ & $r, \tau$ & جميع العبارات معا & \\
\hline
\end{tabular}

وبما أن قاعدة القرار تثير إلى قبول فرض العدم إذا كانت قيمة t المحسوبة اقل من قيمتها الجدولية ورفض فرض العدم إذا كان العكس، وفي ضوء نتائج التحليل الإحصائي السابقة، فأنه نت رفض فرض العدم و قبول الفرض البديل بمستوى ثقة 90\% و و ـ أي أنه يوجد إدراك لدي مسئولي المخاطر بالمصارف التجارية المصرية لأهية المخاطر البيئية المرتبط

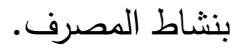


وقد نص الفرض الثاني للبحث علي أنه " لا يتم تضمين المخاطر البيئية المرتبطة

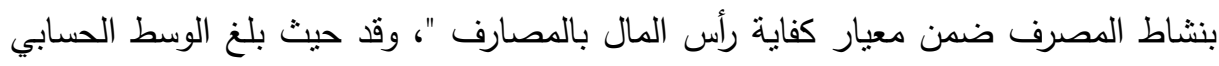
للأسئلة المتعلقة بالفرض مجتمعة Yr.

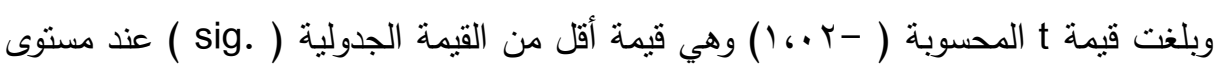

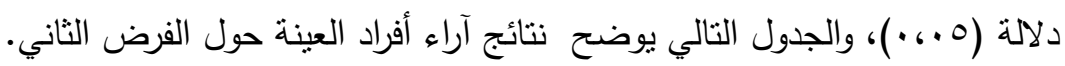

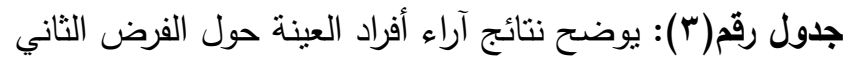

\begin{tabular}{|c|c|c|c|}
\hline المعياري & الحسابط & العبارة & العبارة - ماقم \\
\hline .69 & $r_{6} 7$ & يمنلك المصرف أدوات لقياس وتحليل المخاطر البيئية & V \\
\hline . 69 & $Y_{6} V$ & يمتلك المصرف سياسات معتمدة لإدارة المخاطر البيائية & $\wedge$ \\
\hline .691 & r.9 & 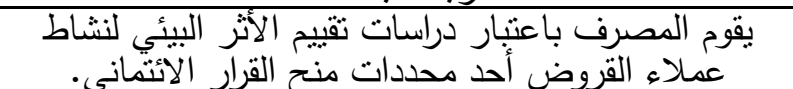 & 9 \\
\hline .697 & T.9 & 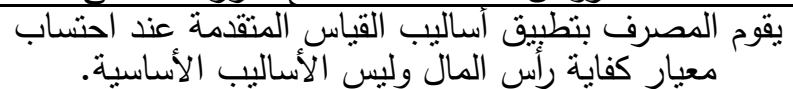 & 1. \\
\hline 161 & $r_{6} 7$ & يتم احتساب رأس مال لمواجهه المخاطر البيئية المتعلقة & 11 \\
\hline $.69 \mathrm{~V}$ & T.V & عبارات معا & \\
\hline
\end{tabular}

في ضوء نتائج التحليل الإحصائي السابقة فأنه نم عدم رفض فرض العدم بمستوى ثقة 90\% ـ أي أنه لا يتم تضمين المخاطر البيئية المرتبطة بنشاط المصرف ضمن فئه معيار كفاية

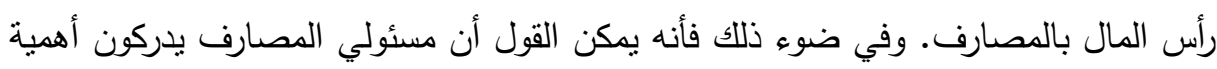

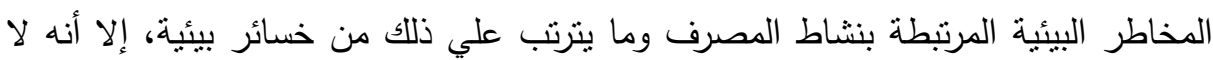

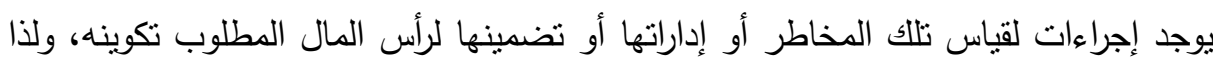
يتتاول المبحث التالي تقديم اطار مقترح لتضمين المخاطر البيئية ضمن معيار كفاية رأس لئ

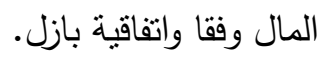




\section{المهيث الرانو}

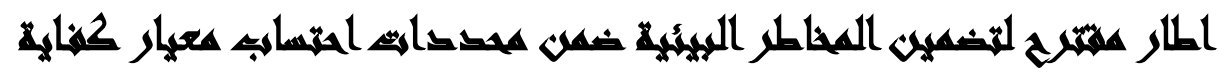
أس المال والمسارهن:

أظهرت الدراسات السابقة تعاظم حدة اثز المخاطر البيئية وما يرتبط بذلك من خسائر

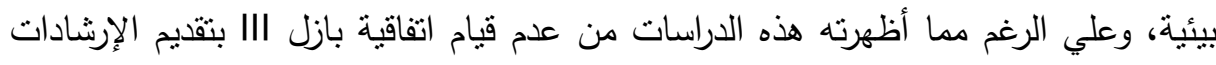

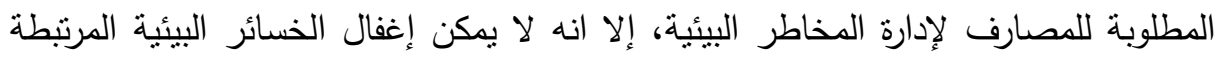

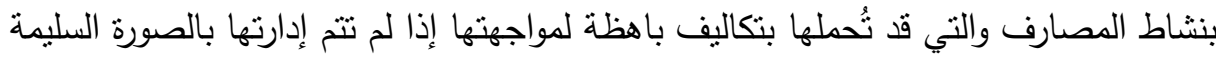
• فمع تتوع الخدمات التي تقدمها المصارف وما اقترن بذلك من تعقد درجة التكنولوجيا

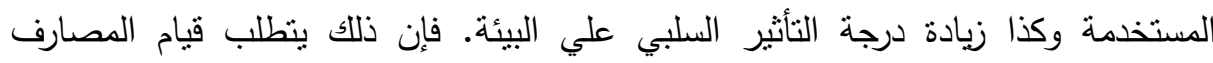

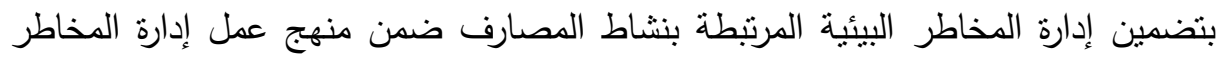

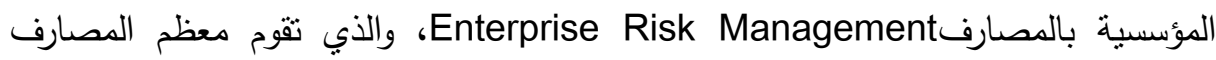

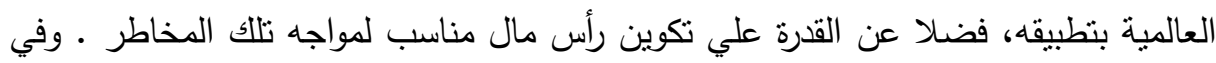

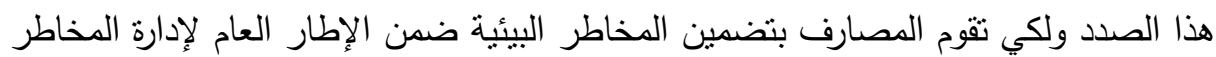

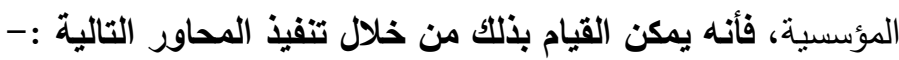
ا ـ تهيئة بيئة إدارة المخاطر بالمصرف لإلهن لإدارة المخاطر البيئية . r. تحديد الأهداف الإستراتيجية من إدارة المخاطر البيئية.

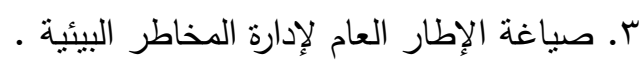

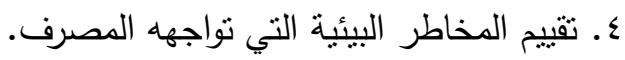
ه. الرقابة علي المخاطر البيئية. 7. احتساب رأس المال اللازم لمواجهه المخاطر البيئية. وفيما يلي عرض لهذه المحاور:

أولا:تهيئة بيئة إدارة المخاطر بالمصرف لهادئ لإدارة المخاطر البيئية: ينم تهيئة بيئة

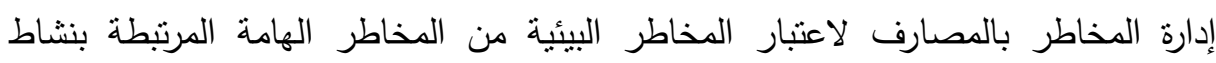


المصرف والمطلوب إدارتها والتحوط لها بتكوين رأس مال مناسب لمواجهه خسائرها أسوة

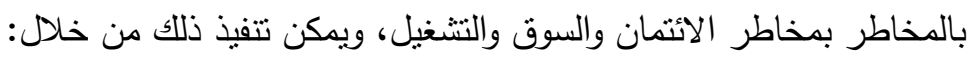

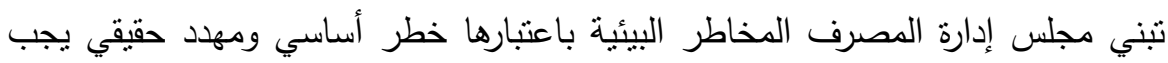
إدارته والتحوط للخسائر المرتبطة بها. أن يلم مجلس إدارة المصرف والعاملين بالمعارف والجوانب الرئيسية للمخاطر البيئية التي يتعرض لها المصرف أو التي يساهم في حدوثها. اعتماد المصرف لمنهج عمل محدد وواضح لإدارة المخاطر البيئية بالمصرف. تعريف وتحديد وتقييم المخاطر البيئية المتعلقة بنشاط المصرف. وضع سياسات وسيناريوهات لإدارة المخاطر البيئية بحيث تكون معتمدة من مجلس إدارة المصرف.

ثانيا: تحديد الأهداف الإستراتيجية من إدارة المخاطر البيئية: يمثل تحديد الأهداف الإستراتيجية لإدارة المخاطر البيئية خطوة محورية في آليات إدارة منل هذا النوع من المخاطر

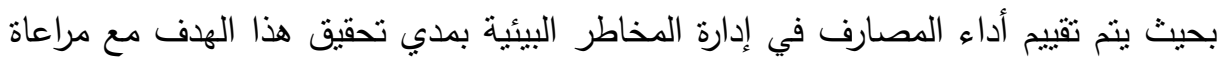
قيام إدارة المصرف بتحديد إستراتيجية التعامل مع المخاطر البيئية، وتحديد الأطر والسياسات المطلوب تطبيقها من اجل تحقيق هذه الأهداف والتي منها:الحفاظ علي مسنوي منخفض من التعرض للمخاطر البيئية .

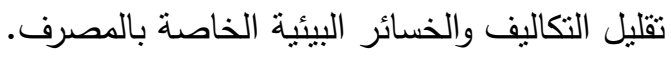
تحقيق استدامة بيئية لأنشطة المصرف. حماية الموظفين والعملاء من التعرض للحوادث التي قد تسبب التهبه الوفاة أو التعرض لإصابات الخطيرة.

ثالثا: صياغة الإطار العام لإدارة المخاطر البيئية: وينم ذلك من خلال تحديد وتعريف الخطر البيئي ثم تحديد الإطار العام الذي سيتم تطبيقه بالمصرف لإدارة المخاطر البيئية . ويمكن تعريف المخاطر البيئية علي أنها " التهديد الفعلي أو المحتمل للكائنات الحية والبيئة في صورة الانبعاث والمخلفات السائلة والصلبة واستنزاف الموارد البيئة، أو تهديد الأفراد أو لهاب

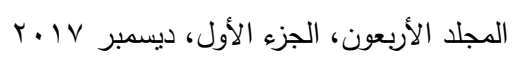


الحيوانات أو النباتات... الخ الناتجة عن ممارسة المؤسسات لأنشطتها الاقتصادية أو ما

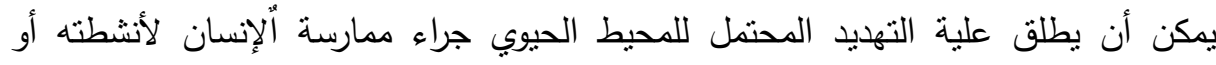

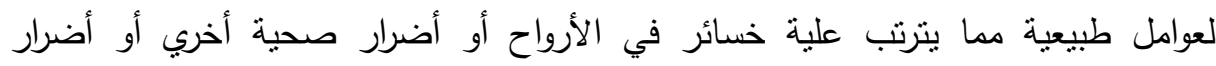
بالممتلكات والبنية التحنية والموارد البيئية وفقدان سبل العيش وتوفئ لإنير الخدمات (2013

.(Building resilience,

وفي إطار هذا التعريف يمكن القول بأن الإطار العام لإدارة المخاطر البيئية هو مزيج متفاعل من إدارة المخاطر علي ثلاث مستويات رئيسية وفقا وما يلي: الإني: ا-علي مستوي أنثطة الائتمان والاستثمار: وجهت لجنة بازل إلي أهمية رصد خطرئ الالنزام البيئي المتعلق بالضمانات التي تحصل عليها المصارف من العملاء، كعدم احتواء هذه الضمانات علي أي مواد سامة أو مشعة تمثل خطرا علي البيئة..... الخ. وبناء علي لئي

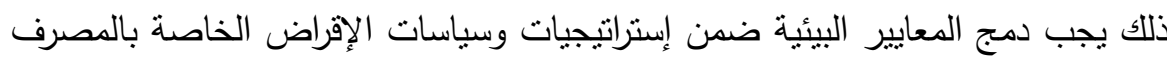
وبحيث تتضمن ما يلي: - تصنيف المشروعات التي ينم تمويلها وفقا ودرجة الخطر البيئي المترتب علي ممارسة المشروع لنشاطه في المجتمع، بحيث يتم الربط بين درجة الخطر البيئي للمشروع والقرار

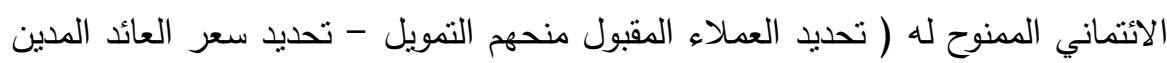

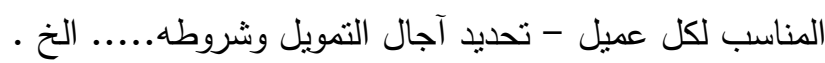

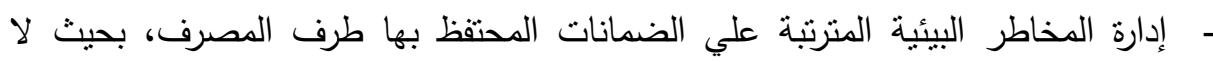
تحتوي هذه الضمانات علي ما يهدد البيئة أو يمثل خطر علي حياة الأفراد أو الحيوانات . كأن يقدم أحد العملاء مخازن أو بضائع تحمل صفات إثنعاعية أو مواد سامة ملوثة للبيئة كضمان عيني يتم الاحتفاظ به وتخزينه والرقابة علية من قبل المصارف. r- علي مستوي سلسة التوريد الخاصة بالمصرف: يجب أن تقوم المصارف بتقبينيم الاستدامة البيئية للموردين من خلال: التحقق من إلمام الموردين بالمخاطر البيئية والاجتماعية المرتبطة بالمنتجات والأنشطة

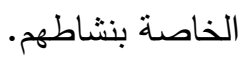


إلمام الموردين بالحد الادني من درجة الوعي في التعامل مع القضايا البيئية والاجتماعية . التحقق من النزام الموردين بالمعايير الدولية في مجال حماية البيئة.

ج - علي مستوي العمليات والأنشطة المباشرة للمصرف: ويتم ذلك من خلال فير فيام إدارة

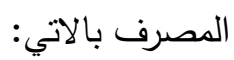
مراقبة / الحد من / الإفصاح عن كلا من ( استهلاك الطاقة - انبعاثات غازات الاحتباس

$$
\begin{aligned}
& \text { الحراري - استهلاك الورق - النفايات - استهلاك المياه) . } \\
& \text { تقديم منتجات وخدمات بيئية للعملاء. } \\
& \text { زيادة الوعي البيئي للعاملين. }
\end{aligned}
$$

رابعا: تقييم المخاطر البيئية التي تواجهه المصرف: تتطلب إدارة المخاطر البيئية قيام المصرف بتقييم هذه المخاطر وتحديد ما إذا كانت هذه المخاطر مقبولة أم تتطلب اتخاذ إجراءات بهدف مواجهة الخسائر البيئية المنوقعة. ويمكن تعريف تقييم المخاطر البيئية بأنه الخطوة التي يتم فيها قياس مدي خطورة كل مخاطرة بيئية بالنسبة للضوابط الرقابية المطبقة

$$
\begin{aligned}
& \text { بهدف التعرف علي الخطر البيئي و تحديد كلا من : - } \\
& \text { عدد مرات نكرار حدوث الخطر البيئي ( احتمالية حدوث الخطر البيئي ). }
\end{aligned}
$$$$
\text { الأثر المالي المرتبط بالمخاطرة البيئية ( الخسائر البيئية ) . }
$$

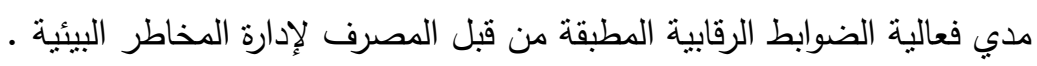

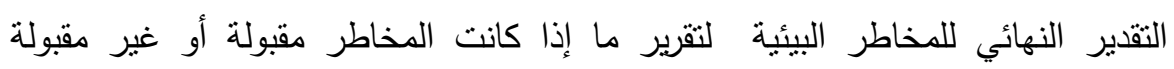

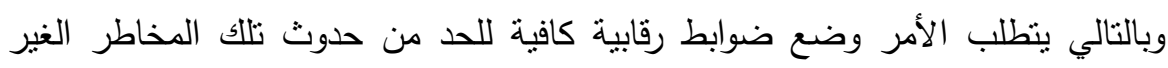

مقبولة (Anne V. Whyte, 1980)

ونظرا لحداثة مفهوم إدارة المخاطر البيئية في المصارف، فأنه يقترح إتباع مناهج بسيطة عند قياس أو تقييم المخاطر البيئية المرتبطة بنشاط المصرف . ومن بين الأساليب البسيطة

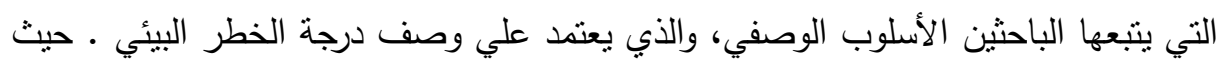
يمكن نطبيق هذا الأسلوب من خلال تتفيذ الخطوات التالية:

$$
\text { المجلد الأربعون، الجزء الأول، ديسمبر Y r. }
$$


ا. إعداد قائمة بكافة المخاطر البيئية المرتبطة بنشاط المصرف ( مخاطر منوقعة أو غير منوقعة ) وذلك من خلال فحص كل نشاط مرتبط بالمصرف وتحديد كافة المخاطر البيئية

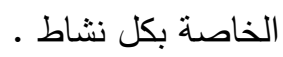

r. تحديد معدل تكرار كل مخاطرة بيئية وذلك من خلال تحديد تقدير مبدئي لمعدل تكرار

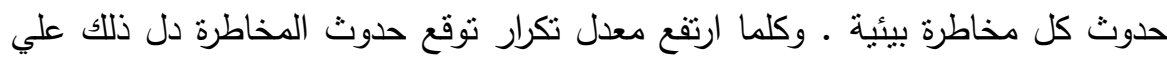
احتمال اكبر للتعرض للخسائر المترتبة علي هذه المخاطرة . ويتم تحديد هذا التقدير

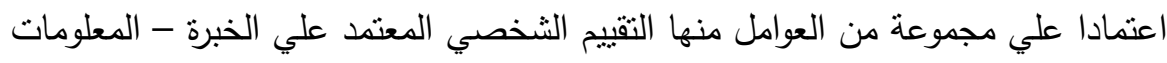
التاريخية عن مخاطر مثيلة - خسائر بيئية حدثت بالفعل للمصرف - التزامات بيئية

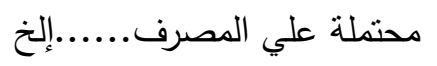
r. تحديد التأثير المالي للمخاطرة البيئية وذلك من خلال تقدير الخسائر البيئية المتوقع تكبدها

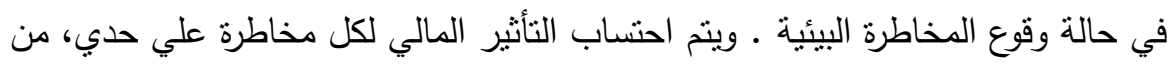
خلال احتساب التأثثر المالي للمخاطرة مضروبا في عدد مرات نوقع حدوث المخاطرة خلال العام . ع. تحديد التقييم النهائي للمخاطرة البيئية وذلك اعنمادا علي كلا من معياري معدل التكرار و التأثير المالي، ثم يتم تصنيف المخاطر البيئية إلي فئتين :-

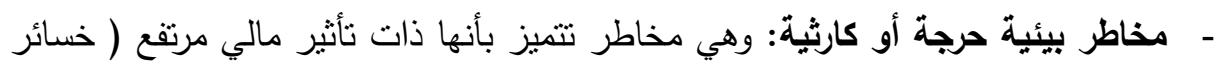
بيئية مرتفعة ) وذات معدل تكرار عالي • وهذه تتطلب من المصارف اتخاذ إجراءات

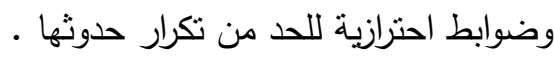

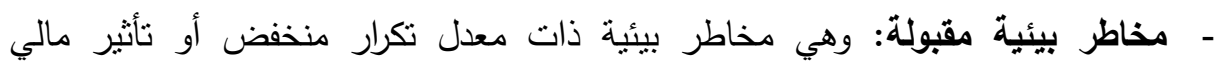
منخفض (خسائر بيئية منخفضة ). خامسا: الرقابة علي المخاطر البيئية: وفي هذه المرحلة ينم اختيار الأسلوب الأمنل

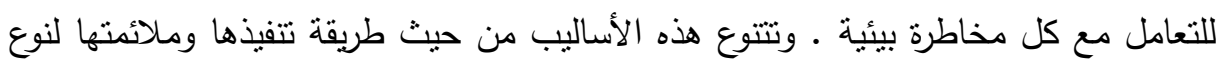

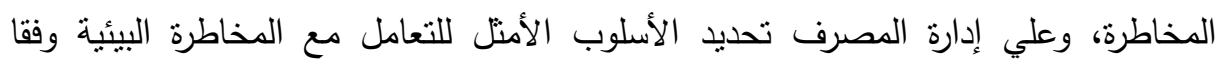

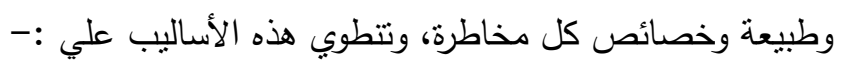


ا. التحكم في الغطر البيئي environmental risk control : وفقا لهذا الأسلوب يقوم المصرف بالتحكم في المخاطر البيئية التي تواجهه من خلال وضع الضوابط الرقابية والإجراءات اللازمة للتقليل من احتمالية حدوث مثل هذا النوع من المخاطر كقيام المصرف بتمويل مشروع ملوث للبيئة مع الأخذ في الاعتبار معالجة التلوث البيئي من منئ المترتب علي هذا المشروع وتمويل وسائل الحد من التلوث المرتبط بنشاطه.

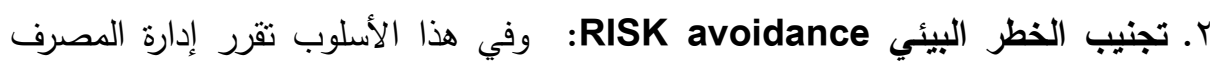
تجنب مخاطرة بيئية معينة من خلال رفض التعامل مع العميل أو النشاط المنشي

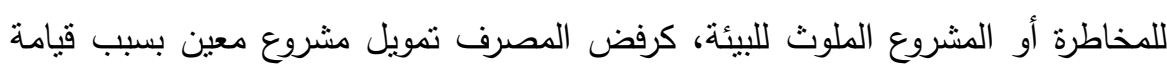
بتلويث البيئة الحيوية المحيطة بالمصنع. r. تحويل الخطر البيئي Risk transfer: وفقا لهذا الأسلوب يقوم المصرف بتحويل باليه المخاطرة البيئية لجهة أخري أكثر استعدادا لتحمل المخاطر البيئية، منل قبام المصرف البئي

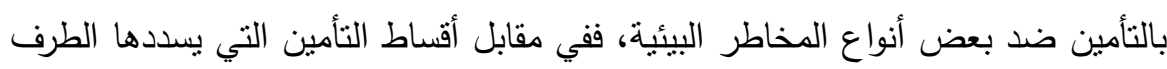

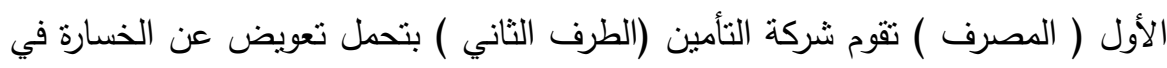
حدود مبلغ معين وفقا والاتفاق فيما بين الطرفين. ع. تقبل الخطر البيئي Risk acceptance : وفقا لهذا الأسلوب ينم قبول التعرض لمجموعة من المخاطر في حدود خسارة محددة دون القيام باتخاذ أي إجراء احترازي ضدها، أي عدم قيام المصرف بأي إجراء إيجابي لتفادي المخاطرة، أو تحويلها أو التحكم

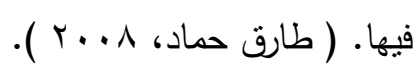
سادسا: احتساب رأس المال اللازم لمواجهه المخاطر البيئية: يمكن للمصارف استخدام العديد من الأساليب الإحصائية لإحتساب رأس المال اللازم لمواجهه المخاطر البيئية،

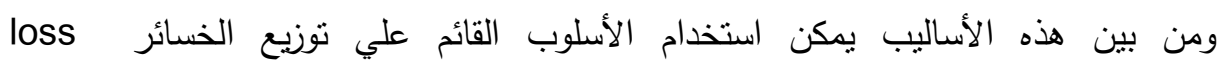
distribution approach . حيث ينيح هذا الأسلوب الاعتماد علي بيانات التاريخية للخسائر في احتساب رأس المال اللازم (A.Frachot , 2001 )، ويتم تطبيق هذا الأسلوب

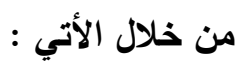

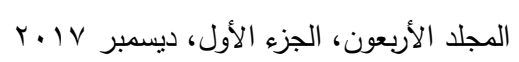


ا ـ تكوين قاعدة بيانات عن الخسائر البيئية المرتبطة بنشاط المصرف: ولذا يجب علي كل مصرف أن يكون لدية قاعدة بيانات يتم فيها تسجيل كافة الأحداث والبيانات المتعلقة

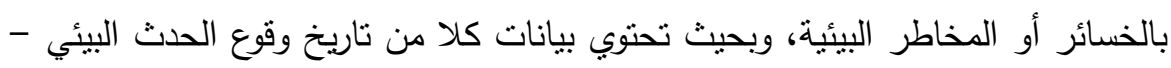
وصف مختصر للحدث البيئي - قيمة الخسائر التي تحملها المصرف- الإجراءات التصحيحية المتخذة من قبل المصرف. r. تحديد وتقييم المخاطر البيئية المرتبطة بكل نثاط للمصرف: وفي هذه المرحلة يتم إعداد

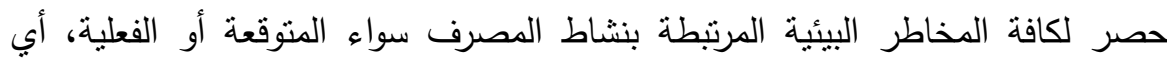
المخاطر البيئية الفعلية التي تعرض لها المصرف أو المخاطر البيئية المحتملة المرتبطة بنثاط المصرف، حيث يتم إعداد نموذج مخاطر لكل أنثطة المصرف والمرتبطة بالمخاطر البيئية، بحيث يحتوبي نموذج المخاطر علي بيانات كلا من ( الخطر البيئي - لبندئ معدل نكرار الخطر البيئي - التأثثر المالي المنوقع للخطر البيئي - التقييم النهائي للخطر البيئي ( حرج - غير حرج ).

r. احتساب رأس المال اللازم لمواجهة الخسائر البيئية.: لكي ينم احتساب رأس المال اللازم

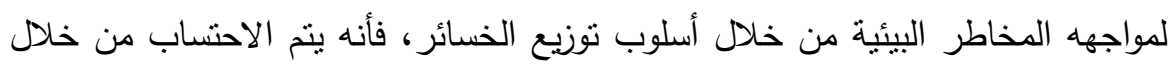
المعادلة التالية: - قيمة رأس المال = قيمة الخسائر البيئية المتوقعة + قيمة الخسائر البيئية الغير متوقعة . حيث أن :-

الخسائر البيئية الغير متوقعة = قيمة الخسائر البيئية الفعلية - قيمة الخسائر البيئية

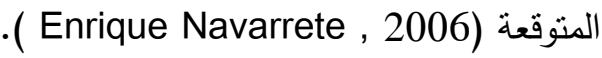

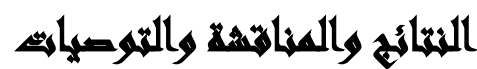

أ- نتائج البحث: تتفق النتائج التي نم التوصل إليها مع ما جاء بالدراسات السابقة، وهي:

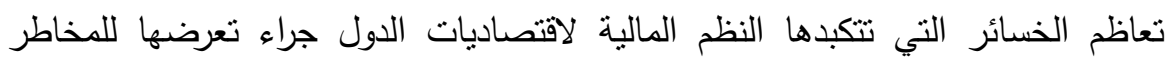
البيئية. 
إدراك مسئولي المخاطر بالمصارف التجارية المصرية للمخاطر البيئية المرتبطة بنشاط المصرف. عدم وجود نظم حالية لإدارة المخاطر البيئية بالمصارف.

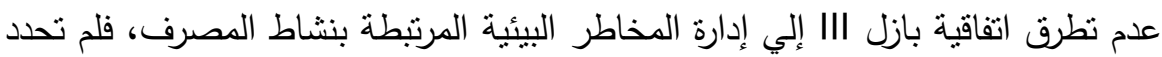

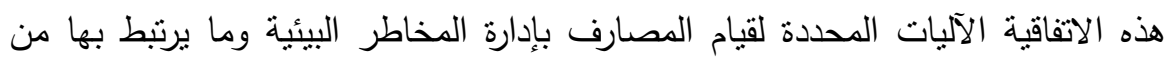

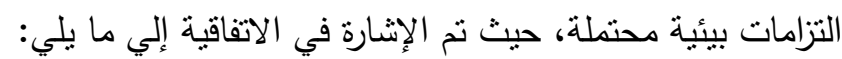
ضرورة التزام المصارف بالقوانين والتشريعات البيئية. أن ترصد المصارف وبشكل مناسب خطر الالتزام البيئي المترتب علي الضمانات الخاصة

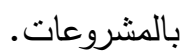

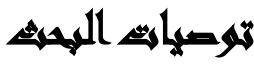

أ - علي مستوي المصارف التجارية:

أن يكون لدي المصرف نظام لإدارة المخاطر البيئية المرتبطة بنشاطه بحيث يتم من خلاله تحديد وقياس وتقييم والحد من المخاطر البيئية المرتبطة بنشاطه. توثيق السياسات والإجراءات الخاصة بضوابط إدارة المخاطر البيئية .

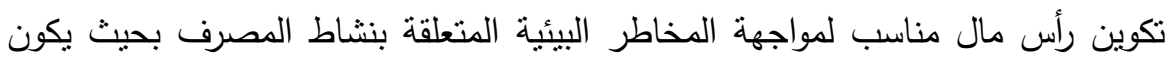
خط دفاع أول لتحمل أي خسائر البيئية.

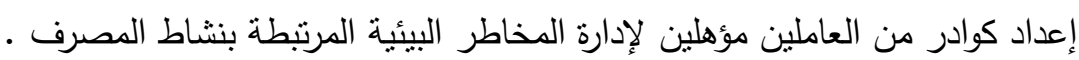
ب - علي مستوي البنك المركزي المصري:

إعداد اطر تفصيلية من قبل مسئولي البنك المركزي المصري يتم من خلالها توضيح آليات إدارة المخاطر البيئية وأسلوب ت تحديد وقياس وتقييم المخاطر البيئية المرتبطة بنشاط

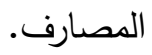

تهيئة الكوادر من العاملين بالبنك المركزي علي مفاهيم إدارة المخاطر البيئية وآليات تطبيق

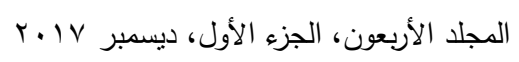


تضمين المخاطر البيئية كأحد المخاطر الرئيسية ضمن إستراتيجية إدارة المخاطر بالقطاع

المصرفي المصري.

تقديم حوافز للمصارف التي يثبت قيامها بإدارة المخاطر البيئية المرتبطة بنشاطها مع إثابة

المصارف علي نشاطها الاجتماعي ودورها في تحقيق التتمية المستدامة.

ج - علي مستوي اتحاد بنوك مصر و المعهد المصرفي المصري:

عقد ورش عمل لتدريب العاملين بالمصارف لمصرفي لتوضيح المفاهيم الأساسية المرتبطة

بالبيئية والمخاطر البيئية والتتمية المستدامة.

إلقاء الضوء حول تجارب المصارف العالمية في إدارة المخاطر البيئية.

\section{المرامئية}

أسامة حسن عبدة ادريس(ى ( ب): دور المسئولية الاجتماعية للمصارف في دعم السياسات

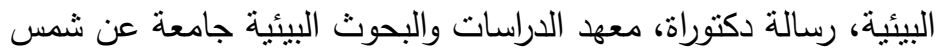

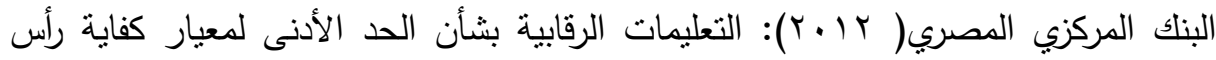

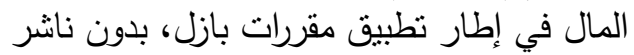

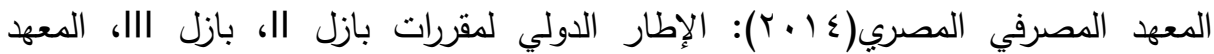

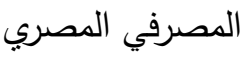

طارق عبد العال حماد(9 . . ؟): حوكمة الثركات والأزمة المالية العالمية،الدار الجامعية .

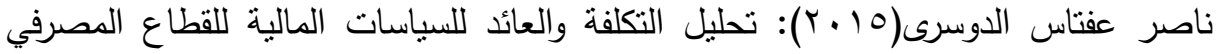

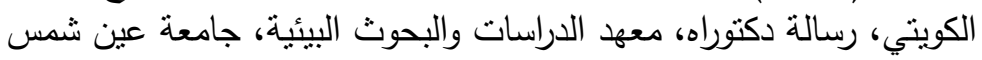

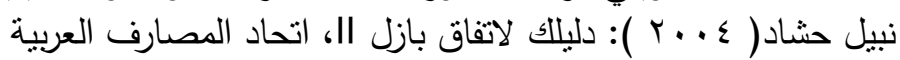

A.Frachot,P.georges . (2001 ), loss distribution approach for operational risk, Group de recherché operationally credit Lyonnais ,

Anne V. Whyte and Ian Burton. (1980), Environmental risk assessment , Scientific Committee on Problems of the Environment.

Bank of International Settlement, Basel Committee on Banking Supervision.(2014), A brief history of the Basel Committee.

Building resilience. (2013): integrating climate and disaster risk into development, the world bank.

$$
\text { المجلد الأربعون، الجزء الأول، ديسمبر VY. T }
$$


يحيي محمد أبو طالب وآخرون

Enrique Navarrete .(2006): Practical Calculation of Expected and Unexpected Losses in Operational Risk by Simulation Methods, Scalar Consulting.

Institute For Sustainability Leadership.( 2014), Are Environmental Risk Missing In Basel, University Of Cambridge.

The world bank.( 2013),Diagnostic assessment of select environmental challenges, an analysis of physical and monetary losses of environmental health and natural resources .

\title{
A PROPOSED FRAMEWORK FOR INCLUDING ENVIRONMENTAL RISKS WITHIN THE DETERMINANTS OF CALCULATING CAPITAL
} ADEQUACY IN BANKS

\author{
Abotaleb, Y M. ${ }^{(1)}$; Mohamed, M. A. ${ }^{(2)}$ and Sayed, S. S..$^{(3)}$ \\ 1) Faculty of Commerce, Ain Shams University 2) Faculty of \\ Commerce, Kafr El Sheikh University 3) National Bank of Egypt
}

\begin{abstract}
Basel III has directed banks to manage the significant risks associated with their activity. Banks and Basel III have focused on managing both credit, market, operational and liquidity risks as the most common risks in the banking industry. Banks have therefore set up appropriate capital to counter these types Of risk, to be capital as the first line of defense to absorb any losses resulting from exposure to banking risks.
\end{abstract}

Despite the diversity of environmental risks associated with the banks' activity as well as the increase in their effects, which amounted to direct losses only in 2011 about 400 billion dollars, for a number of not more

$$
\text { المجلد الأربعون، الجزء الأول، ديسمبر r. V r. }
$$


than 1,600 accidents or environmental disaster only according to the study prepared by the World Bank (2013 Building resilience) . However, the decisions of the Basel III Committee did not take these risks into consideration when issuing their regulatory instructions to banks.

The objective of the research is to clarify the nature of the environmental risks associated with the Bank's activity and associated environmental losses, while providing a proposed framework for including environmental risks within the parameters of calculating the capital adequacy standard in banks and in accordance with the general framework of risk management in banks. The search for questions answered the nature of the environmental risks associated with the activity of banks and to what extent banks are calculating capital to face environmental risks.

Data collection was based on the use of a questionnaire questionnaire that was directed to the sample of the study from managers and officials of risk departments in commercial banks operating in the Arab Republic of Egypt. A total of 50 completed questionnaire forms were received. The data were analyzed through the use of the statistical packages for social studies (SPSS). The first hypothesis of the research, which stated that there is no awareness among the Egyptian commercial banks of the environmental risks associated with the Bank's activity, was not true. The second hypothesis states that "the environmental risks associated with the Bank's activity are not included in the bank's capital adequacy criterion" .

The research has reached a number of results, the most important of which are the awareness of the risk managers in the Egyptian commercial banks of the environmental risks associated with the Bank's activity, as well as the absence of existing environmental risk management systems in banks. The study also presented a set of recommendations, the most important of which is the documentation of policies and procedures for environmental risk management controls, the formation of suitable capital to meet the environmental risks related to the bank's activity, so that it is the first line of defense to bear any environmental losses.

$$
\text { المجلد الأربعون، الجزء الأول، ديسمبر V Y. T }
$$

